Boston University School of Law Scholarly Commons at Boston University School of Law

Faculty Scholarship

$1-1-2014$

\title{
Exploring the Relationship between Consent, Assumption of Risk, and Victim Negligence
}

Kenneth Simons

Boston Univeristy School of Law

Follow this and additional works at: https://scholarship.law.bu.edu/faculty_scholarship

Part of the Torts Commons

\section{Recommended Citation}

Kenneth Simons, Exploring the Relationship between Consent, Assumption of Risk, and Victim Negligence, Philosophical Foundations of the Law of Torts 272 (2014).

Available at: https://scholarship.law.bu.edu/faculty_scholarship/17 


\section{BU School of Law}

\section{EXPLORING THE RELATIONSHIP BETWEEN CONSENT, ASSUMPTION OF RISK, AND Victim NEGLIGENCE}

In John Oberdiek, ed., PHILOSOPHICAL FOUNDATIONS OF THE LAW OF TORTS

(2014, Forthcoming)

Boston University School of Law Working Paper No. 13-45

(September 3, 2013)

Kenneth W. Simons

Boston University School of Law

This paper can be downloaded without charge at:

http://www.bu.edu/law/faculty/scholarship/workingpapers/2013.html 
Exploring the Relationship between

\section{Consent, Assumption of Risk, and Victim Negligence}

by

Kenneth W. Simons ${ }^{1}$

\section{Introduction}

What is the relationship between the following three legal doctrines?

- Consent as a defense to an intentional tort (henceforth, “consent (IT)”);

- Assumption of risk (AR) as a defense to negligence;

- Contributory negligence (CN), i.e., the victim's failure to use reasonable care with respect to his own safety, as a defense to negligence and to an intentional tort.

Should these doctrines be no defense, a partial defense, or a full defense? If it depends, on what does it depend?

Consider five examples.

\section{The death of Houdini}

Harry Houdini, the extraordinary magician and escape artist, performed numerous feats of physical endurance for his various audiences, some of them quite astonishing. One of his more prosaic feats turned out to be fatal.

Houdini was known to dare others to punch him as hard as they could in the stomach. On October 20,1926, after a public performance, a college student met him in his dressing room, took up the dare and delivered several strong blows to his stomach. Those blows may well have caused his death a short time thereafter. $^{2}$

\footnotetext{
${ }^{1}$ Professor of Law and The Honorable Frank R. Kenison Distinguished Scholar in Law, Boston University School of Law. Email: ksimons@bu.edu(C) 2012. All rights reserved. I am grateful to participants at the Conference on the Philosophical Foundations of the Law of Torts, sponsored by Rutgers Institute of Law and Philosophy, November 2012, for their helpful reactions. Special thanks to Kim Ferzan, who commented on the paper at the conference, and to Michelle Dempsey.
}

2 The circumstances of Houdini's death are hotly contested. It is not clear whether the punches to the stomach were a but for cause of his death, or whether the appendicitis that was diagnosed soon thereafter, and which led to the peritonitis that led to his death, would have caused the death apart from the blows. Also in dispute is whether the punches were truly consensual: on some accounts, the person who punched Houdini approached him so suddenly that he did not have time to tighten his abdominal muscles in preparation for the blows. See http://www.snopes.com/horrors/freakish/houdini.asp (accessed 9.18.12); The Life and Death of Harry Houdini, http://www.npr.org/templates/story/story.php?storyId=1485266; 
If Houdini's estate had sued the student for the intentional tort of battery, the student would undoubtedly have relied on the defense of consent. Should this be a (partial or complete) defense? Should it be a defense only if it was unreasonable, rather than reasonable, for Houdini to agree to be punched in the stomach?

\section{Jane, a pedestrian fleeing from danger}

An armed robber is chasing Jane. Her only escape route is across a street busy with vehicular traffic. Rushing into the traffic, she is struck by the car of speeding driver Jill.

If Jane sues Jill, should Jill be able to rely on the defense that Jane chose the risk of injury from traffic over the risk of injury from the robber? Should this be a (partial or complete) defense only if it was unreasonable, rather than reasonable, for Jane to act as she did?

\section{Yin, a pedestrian in a hurry}

Yin is running late for the closing time of his child's daycare center. So is Yang. Yin hurries across a busy street. Yang drives above the speed limit. Yang's car strikes Yin.

If Yin sues Yang, should his behavior be a (partial or complete) defense only if it was unreasonable, rather than reasonable, for Yin to act as he did?

\section{Pascal, a passenger in a very great hurry}

Rascal offers his friend Pascal a ride to the airport. At the start of the drive, Pascal mentions that he is running very late for his plane, and strongly urges Rascal to speed 20 miles per hour over the speed limit. Rascal does so. In the ensuing crash, Pascal is badly injured.

\footnotetext{
Obituary: Harry Houdini Dies After http://www.nytimes.com/learning/general/onthisday/bday/0324.html; October 31, 1926: Death Proves Inescapable for Even Houdini, http://blogs.smithsonianmag.com/aroundthemall/2011/10/october-31-1926death-proves-inescapable-for-even-houdini/. For purposes of this article, please assume that Houdini did agree to be punched in the stomach in just the way that he was actually punched; and that the punches caused his death.
} 
If Pascal sues Rascal, should Pascal's behavior be irrelevant to liability, a partial defense, or a complete defense?

\section{Scott, the extreme skater}

Dot, the operator of a public skating rink, improperly prepares the ice, leaving it very rough, and thus unusually dangerous to most skaters. She puts up a sign: "Dangerous rough ice. Sorry. Skate at your own risk. Will be fixed by tomorrow." Scott, who is preparing for an outdoor race on ice in very similar conditions, decides to skate around the rink. Due to the rough ice, he falls and suffers injury. ${ }^{3}$

If Scott sues Dot, should his behavior be a (partial or complete) defense only if it was unreasonable, rather than reasonable, for him to continue to skate?

The most defensible answers, as we shall see, are as follows:

(1) Consent or AR is a complete defense; if consent is found, the reasonableness of plaintiff's conduct is irrelevant.

(2) No consent or AR defense. Reasonableness is relevant, but plaintiff's conduct is reasonable, so damages should not be reduced.

(3) No consent or AR defense. Reasonableness is relevant, and plaintiff's conduct is unreasonable, so damages may be reduced.

(4) Consent or AR is a complete defense.

(5) Consent or AR is a complete defense.

To explain this pattern of answers, we need to explore some fundamental questions about the concepts of consent and fault, about their respective rationales, and about their interrelationship. Section II briefly reviews the legal background. Section III explores the phenomenology and structure of consent, especially the following question. When a person legally consents to conduct $\mathrm{x}$, and knows that there is a significant risk that $\mathrm{y}$ will occur (where $\mathrm{y}$ is conduct similar to $\mathrm{x}$, or is a harmful result of $\mathrm{x}$ ), should we conclude that he also legally consent to $y$ ? This is a surprisingly common situation, yet there is surprisingly little discussion about how to resolve it. Often, we will see, by

\footnotetext{
${ }^{3}$ The example is loosely based on the case of Meistrich v. Casino Arena Attractions, Inc., 155 A.2d 90 (N.J. 1959). See Kenneth W. Simons, "Reflections on Assumption of Risk," 50 UCLA L. Rev. 481 (2002), 490.
} 
legally consenting to $\mathrm{x}$, a person is properly treated as legally consenting to the "package" of [x plus the risk of $y$ ]. But whether she is properly deemed to accept such a "package deal" depends crucially on the nature of the tort in question.

Section IV carefully examines whether and how consent (IT) and AR can be distinguished. Why is the reasonableness or unreasonableness of the victim's conduct relevant in some cases but not others? Why does reasonableness seem more relevant when the victim decides to encounter a negligently-created risk—cases (2), (3), (4), and (5) - than when the victim decides to permit a physical contact or intrusion that would otherwise be an intentional tort-case (1)? Whether Harry Houdini acted prudently or foolishly in allowing someone to punch him in the stomach seems irrelevant to his estate's claim for recovery. If he genuinely consented, surely recovery should be precluded, even if his decision was reasonable. Doctrinally, this first puzzle resolves into the question: Why is AR such a disfavored defense today? We will see that the treating AR and consent (IT) differently is sometimes justified, but at the same time, their shared underlying rationale too often is ignored.

Two preliminary notes. First, the term "consent" is notoriously ambiguous. We must distinguish between the minimal concept of assent, which is, roughly, a preference or willingness that the conduct occur; and the more robust concept of legally binding consent, which is assent given with sufficient knowledge, competence, and freedom of choice. $^{4}$ In this paper, the context should clarify which concept is at issue. Second, the paper explores the range of contexts in which consent (IT) or AR should be a defense, but, for reasons of space, does not explore the situations in which consent is legitimately ignored or overridden for compelling paternalistic or other reasons.

\section{Legal background}

The basic story of the evolution of contributory negligence (CN) from complete to partial defense is well known. Through most of the $20^{\text {th }}$ Century, both CN and AR served as complete defenses. But widespread discomfort with the harshness of these

\footnotetext{
${ }^{4}$ See Peter Westen, The Logic of Consent (Ashgate, 2004); Kenneth Simons, "Book Review: The Conceptual Structure of Consent in Criminal Law,” 9 Buff. Crim. L. Rev. 577 (2006), 580-581.
} 
rules caused almost all Anglo-American jurisdictions to reject the all-or-nothing CN rule with rules of comparative responsibility that permit many plaintiffs who would previously have been barred to recover a portion of their damages. ${ }^{5}$

However, rejecting the all-or-nothing remedial consequence of $\mathrm{CN}$ leaves unresolved the status of AR. Most American jurisdictions also abolished AR, "merging” it into the new comparative responsibility rules. If the plaintiff acted unreasonably, he might obtain partial recovery. If he acted reasonably, he would obtain full recovery. Some Anglo-American jurisdictions continue to recognize AR, but they usually interpret it extremely narrowly. In England and Canada, for example, AR is usually taken to require that the plaintiff agreed, not just to accept the physical risks of injury, but to accept the legal risks: the defendant must show that the plaintiff specifically intended to waive his legal right to sue.

It is understandable that so many courts have merged AR into comparative fault or have interpreted AR very narrowly: a broad interpretation of AR leads to patently unjust results. For example, in cases where the victim reasonably chooses to rescue herself (recall Jane), or to rescue another, a broad interpretation of AR results, not just in a reduction of the victim's recovery, but in a complete denial of liability. ${ }^{6}$ In the early $20^{\text {th }}$ Century, especially, broad interpretations of AR frequently led to unconscionable results for employees: if they had the temerity to complain about an unsafe condition in the workplace, the very fact of the complaint underscored their awareness of the risk and thus made the defense of AR easy to establish.

\footnotetext{
${ }^{5}$ To be sure, even after the advent of comparative fault, many jurisdictions continue to employ an all-ornothing rule when the victim is negligent but the injurer commits an intentional tort; this categorical rule ignores victim fault and permits full recovery. However, some jurisdictions have relaxed this rule, permitting comparative apportionment between an intentional tort and negligent conduct, especially when the negligent conduct is committed by a co-defendant rather than by the plaintiff, and especially when the "intentional" tort does not express a serious type of fault.

${ }^{6}$ For a recent example of such an unjust result, see Duda v. Phatty McGees, Inc., 758 N.W.2d 754 (S.D. 2008), concluding that it was a question for jury whether a customer at a bar assumed the risk of the bar's negligently inadequate security when he stepped in front of friend to protect him from a broken beer bottle during a fist fight. Here is the court's dubious reasoning:

He deliberately placed himself between his friend and two assailants. Heroism can exact a high cost. Coming to the aid of an outnumbered friend in a fight, though understandable, and even commendable, still reflects a conscious decision to inject oneself into a volatile and dangerous situation. Id. at 759 .
} 
AR has had a bad rap, for good reason. The versions of AR that many courts traditionally endorsed are unduly broad. But narrower versions of $A R$, versions that express a genuine consensual rationale for precluding recovery, are much more justifiable. In my own writing, I have endorsed a narrow "full preference" approach to AR and consent (IT). ${ }^{7}$ Under this approach, AR would be a bar only if P preferred the option that $\mathrm{D}$ negligently offered to the option that $\mathrm{P}$ would have confronted if $\mathrm{D}$ had not been negligent. Pascal and Scott are thus valid cases for AR: Pascal preferred that Rascal drive at high speed, rather than at a safe speed; Scott preferred to skate on the negligently-prepared rough ice than on properly prepared ice.

It is not surprising, then, that AR is currently disfavored. What is surprising is the failure of courts and academics to reconcile the feeble condition of AR with the robust health of consent to an intentional tort ("consent (IT)"). The feeble state of AR is due in significant part to the view that a victim's conduct should reduce his recovery only if that conduct was unreasonable. Yet unreasonableness is not part of the criterion for consent (IT), whether the tort is battery, false imprisonment, trespass to land, trespass to chattels, or invasion of privacy. Harry Houdini's consent to a punch in the stomach (a battery) is a complete defense, even if a jury would conclude that this decision— to expose himself to punches in the stomach with the accompanying risk of injury for the sake of a modest benefit to his career-was shrewd rather than foolish. The same is true of Houdini's consent to what would otherwise be a false imprisonment—by agreeing to be confined and shackled in his famous Water Torture Cell, ${ }^{8}$ for example. Similarly, when a patient genuinely consents to cosmetic surgery, or to surgical option A rather than $\mathrm{B}$, she cannot recover, whether or not a jury would conclude that a reasonable person would not agree to that procedure.

Just as consent (IT) can bar recovery even though, in consenting, the party acted reasonably, obviously a party can fail to consent (IT) even though that failure might be viewed as unreasonable. (Suppose she refuses life-saving medical treatment for no good reason.) Moreover, a victim's conduct can be unreasonable quite apart from the

\footnotetext{
${ }^{7}$ See Kenneth Simons, "Assumption of Risk and Consent in the Law of Torts: A Theory of Full Preference," 67 B.U. L. Rev. 213 (1987); Simons, Reflections.

${ }^{8}$ Houdini would be suspended upside-down in a locked glass-and-steel cabinet full of water. The act required him to hold his breath for more than three minutes.
} 
connection of that conduct to consent or nonconsent. Inadvertently walking into a road full of traffic is almost always unreasonable conduct whether or not the pedestrian would have consented to the risks had he adverted to them. In sum, consent and unreasonable conduct are distinct concepts, and provide distinct reasons for denying or reducing tort recovery: some fact patterns instantiate both, but others instantiate only one or the other.

Below, we will examine more carefully why AR is so disfavored relative to consent (IT). But first, we need to better understand what consent, in either guise, is.

III. The phenomenology and structure of consent

Philosophers and legal academics have vigorously disputed the correct phenomenology of consent as a moral and legal matter. ${ }^{9}$ Is it a subjective mental state? An act of willing? An attitude of acquiescence? Indifference? Is it a preference? A communication? They also disagree about what kinds of mistake vitiate consent, and, more affirmatively, about how closely the consenting actor's belief, desire, attitude, or communication about the conduct, act, or result assented to must match the conduct (or other consent object) that actually occurs, in order to count as morally or legally adequate consent.

The bare outlines of tort doctrine here are relatively clear, though the generality with which the doctrine is stated obscures important difficulties. Consent is "willingness in fact" that tortious conduct occur. ${ }^{10}$ The actor's assent does not count as legal consent unless it is sufficiently voluntary and knowing. Tort law adopts a subjective conception of consent, though it also recognizes "apparent” consent (where the defendant reasonably believed that the plaintiff subjectively consented, even if plaintiff did not). ${ }^{11}$

I believe that the moral conception of consent defended by Larry Alexander best explains and justifies tort law's conception: consent is a subjective state of mind, a

\footnotetext{
${ }^{9}$ See, e.g., Larry Alexander, "The Moral Magic of Consent (II)," 2 Legal Theory 165 (1996), 166; Heidi Hurd, "The Moral Magic of Consent," 2 Legal Theory 121 (1996); Alan Wertheimer, Consent to Sexual Relations ch. 7 (Cambridge, 2004) (defending a performative account); Peter Westen, The Logic of Consent.

${ }^{10}$ Restatement (Second) of Torts §892(1).

${ }^{11}$ Is an external communication of consent to defendant not only sufficient but also necessary to preclude liability? This is a separate and unresolved question. For an argument that private, uncommunicated consent should sometimes ground tort liability, see Simons, "Consent and Assumption of Risk in Tort and Criminal Law" (draft).
} 
conscious forgoing of moral objections to otherwise wrongful conduct. ${ }^{12}$ But what kind of choice, preference, or acquiescence should be necessary for purposes of tort law? The answer here will often differ from the answer appropriate to the moral domain. In the moral sphere, for example, it might be correct to describe an interaction between A and B as nonconsensual whenever B knows of a fact unknown to A that would cause A not to consent and fails to disclose that fact. But in tort law, mistake or fraud vitiates consent only if it pertains to an "essential" rather than "collateral" matter. ${ }^{13}$ Thus, a misrepresentation of motives will not vitiate consent. Suppose B lies and says, "Yes, I really love you,” as an inducement to A to consent to sexual intercourse. This does not, without more, demonstrate that A has not legally consented.

Moreover, whatever we decide is the most appropriate mental state, attitude, or communication to satisfy legal consent standards, a critical additional issue is how closely that mental state must "match" the world. If A agrees with B to play a game of "touch football," they might fail to agree about what kinds of "touches" they contemplate. Only those contacts that are necessary to tag the other player? Or, in addition, incidental bumps while running towards another player? Hard tackles? ${ }^{14}$

To answer the matching question, it might seem that we should require a precise meeting of the minds between the victim and injurer, or at least a description of the conduct consented to that precisely matches the conduct that actually occurs. But these requirements are too demanding. Consider the criterion suggested by the Restatement (Second) of Torts:

In order to be effective, the consent must be to the particular conduct of the actor, or to substantially the same conduct. Thus consent to a fight with fists is not consent to an act of a very different character, such as biting off a finger, stabbing with a knife, or using brass knuckles. Very often the question whether the particular conduct is within the scope of the consent given becomes a question of degree. Minor differences in degree or extent, such as the fact that the force exerted by the actor in delivering a blow is slightly greater than would ordinarily

\footnotetext{
12 Alexander, Moral Magic, at 166.

13 This bears some similarity to criminal law rape doctrine, under which "fraud in the factum" (about the nature of the sexual act) vitiates consent but "fraud in the inducement" (e.g. about the defendant's motives) does not.

${ }^{14}$ As Hurd explains, whether $\mathrm{D}$ has consented to an act $\mathrm{x}$ or a consequence $\mathrm{y}$ is a de dicto rather than de re question: it depends on the description of $\mathrm{x}$ and $\mathrm{y}$. Hurd, Moral Magic, at 126-127.
} 
have been contemplated, usually will not be held to exceed the consent, although a much greater force would clearly exceed it. ${ }^{15}$

Why not limit legal consent to where $\mathrm{P}$ assents to precisely the conduct that occurs? Why should we treat $\mathrm{P}$ as consenting to any deviation from what he expected to occur, even an "insubstantial" deviation? Difficulties of proof no doubt are a partial answer, but I don't think they are the complete explanation. Even if we were absolutely certain that Houdini expected only an average punch in the stomach, we should not permit him to recover if the punch exerted $20 \%$ more force than that. One reason is the unfairness of expecting the puncher to calibrate his force that closely, which might be very difficult or impossible to do. Another is the concern that insisting on a very precise match between the parties' expectations and their conduct would undermine the autonomy and efficiency values that the social practice of legal consent serves.

And this suggests a broader point. Consent in the law very often amounts to a "package deal" in the following sense: $\mathrm{P}$ consents to $\mathrm{x}$ [the species of physical conduct that would, absent consent, amount to the relevant tort], aware that there is some risk of an insubstantial deviation in conduct from $\mathrm{x}$, and some risk of an untoward consequence of $\mathrm{x}$ occurring. Call such a deviation or consequence $\mathrm{y}$. P rarely consents to $\mathrm{y}$ in the fuller sense that he consents to $\mathrm{x}$. Although he might prefer $\mathrm{x}$ to all alternatives, or might acquiesce to $\mathrm{x}$ occurring, considered by itself, often he will not have a comparably favorable or willing attitude towards $y .{ }^{16}$ So when we say that $\mathrm{P}$, by voluntarily and knowingly consenting to $\mathrm{x}$, thereby consents to $\mathrm{y}$, often we mean only that the relationship of $\mathrm{x}$ and $\mathrm{y}$ is sufficiently close, and well enough understood by $\mathrm{P}$, that it is just to deny $\mathrm{P}$ recovery for $\mathrm{y}$ as well as for $\mathrm{x}$. By consenting to $\mathrm{x}, \mathrm{P}$ is deemed to consent

\footnotetext{
${ }^{15}$ Restatement (Second) of Torts §892A, comment c (emphasis added). The black letter of this provision states: "To be effective, consent must be... to the particular conduct, or to substantially the same conduct." Id., Restatement (Second) of Torts §892A(2)(b).

${ }^{16}$ Peter Westen argues that "consent to the risk of y" does not exist unless P consented to (a certainty of) y itself occurring. See Westen, Logic of Consent, 280-284, discussed in Simons, Conceptual Structure, at 621-629. But that is a very strict interpretation of what constitutes consent, much stricter than courts and commentators ordinarily employ. And it is quite coherent and defensible to view someone as consenting to a risk of y even though he did not or would not consent to a high probability or certainty of y. Nevertheless, Westen's argument does underscore the importance of providing an adequate explanation of when it is justifiable to hold that P's consent to $\mathrm{x}$, knowing that thereby he is creating a risk of $\mathrm{y}$, also should be treated as precluding recovery for $\mathrm{y}$ if it occurs.
} 
to the package of [x plus the risk of $\mathrm{y}$; ; and this, in turns, means that $\mathrm{P}$ has no legal complaint about suffering result y if the known risk of y is realized.

Thus, when Houdini agrees to be punched in the stomach, he undoubtedly knows that the punch might be a bit more forceful than average, and also undoubtedly knows that by permitting a punch he is therefore risking a stomach injury. What he actually assents to (and legally consents to) is a punch; he assents (in a different and weaker sense) to the risk of a slightly more forceful punch or of a stomach injury; and he thereby does not have, and should not have, any valid legal complaint if the more forceful punch or the injury actually occurs. We thus reach a somewhat surprising conclusion: many consent (IT) cases actually involve consent or AR with respect to a risk of harm, in this important sense: when P legally consents (IT) to a touching, or to a confinement, often P should also be deemed to have legally "assumed” or consented to a risk (typically only a small risk) of a slightly different touching or confinement, or of further physical harm. Ordinarily, however, an actor who consents to a physical contact should not be deemed to consent to a very high probability of physical harm. ${ }^{17}$ When Houdini tells a stranger, “Go ahead, punch me as hard as you can,” it would not be plausible (absent further facts) to interpret this as legally valid consent that the stranger would use hidden brass knuckles or a knife.

Of course, the package deal expansion of consent (from $x$ to the risk of $y$ ) means that if $\mathrm{P}$ does not consent to $\mathrm{x}$, then he cannot be deemed to consent to the risk of $\mathrm{y}$; thus, $\mathrm{P}$ is not, on that basis alone, precluded from suing for $\mathrm{y}$ when it occurs. ${ }^{18}$ Indeed, depending on the content and scope of the tort right, and the causal relationship of $\mathrm{x}$ to $\mathrm{y}$, P's nonconsent to $\mathrm{x}$ will often provide a basis for P's recovery for $\mathrm{y}$ if it occurs as a result of $\mathrm{x}$.

The significance of the "package deal" expansion of consent from $\mathrm{x}$ to $\mathrm{y}$ is not widely appreciated. We like to think that consent requires assent to precisely the conduct that P confronted or to precisely the consequence that befell him. Yet actors are often (and justifiably) deemed to legally consent even when such assent is lacking. I might prefer to ride the subway without any risk of physical contact, and indeed I might

\footnotetext{
${ }^{17}$ This obviously depends on the context. In medical operations, patients often do consent to a high risk of a seriously harmful side effect.

${ }^{18} \mathrm{P}$ might still retain a negligence claim against $\mathrm{D}$ for creating an unreasonable risk of $\mathrm{y}$.
} 
vociferously announce this preference to other riders; and yet, despite the absence of my actual or even apparent consent, I will be deemed to consent to the minor physical contacts that predictably occur in this context. ${ }^{19}$ I might prefer to play the quarterback position in football without ever being touched, or without any risk of injury, but if I choose to play the game, I will be deemed to consent to the package of inherent risks of the game. In short, in many of the examples we have been considering, especially when $\mathrm{y}$ is a harmful consequence of $\mathrm{x}, \mathrm{P}$ assents to $\mathrm{x}$ despite the risk of $\mathrm{y}$; for $\mathrm{P}$ is often quite unwilling that y occur, and indeed wishes that he could avoid any risk of y. Nevertheless, as a matter of law, his actual assent to $\mathrm{x}$ is deemed to amount to a legal consent to the risk of y (and thus constitutes a legal consent to y if y occurs). From a broader perspective, P's consent to conduct $x$ often entirely vitiates the wrongfulness of that conduct, while his consent to the risk of harmful result y only rarely (if ever) eliminates the harmful quality of that result. So if consent justifiably precludes recovery in the latter scenario, it will do so because of the "package deal" argument (or because of a comparably strong justification).

However, not all tort cases in which the issue of consent arises have this "package deal" structure. In many intentional tort cases, the victim is entitled to a damages remedy without any proof that he suffered physical or even emotional harm as a result of the tortious invasion. ${ }^{20}$ Thus, if $\mathrm{P}$ is intentionally touched or is intentionally confined without his consent, that alone warrants a damage remedy; P need not prove a resulting physical or emotional harm (y).

What, then, is the requisite connection between $\mathrm{x}$ and the risk of $\mathrm{y}$ that justifies treating legally adequate consent to $\mathrm{x}$ (that also creates a risk of $\mathrm{y}$ ) as also amounting to legally adequate consent to y, if y occurs? The answer crucially depends on context—on the nature of the interests furthered or protected by the particular legal right, and also on the nature of the activity in question. The necessary and sufficient conditions for consent in criminal law, contract law, and tort law obviously differ. ${ }^{21}$ Within tort law, the

\footnotetext{
${ }^{19}$ Courts sometimes employ the category "implied-in-law" consent for this type of case. The category is more widespread than generally appreciated. See also Westen, Logic of Consent, at 272-278, 322 (discussing the concept of "constructive consent"), discussed in Simons, Conceptual Structure, at 616-621.

${ }^{20}$ See Dan B. Dobbs, Paul T. Hayden, and Ellen M. Bublick, The Law of Torts $§ 47$ (West: $2^{\text {nd }}$ ed. 2011).

${ }^{21}$ For example, in many jurisdictions consent to an illegal fight precludes tort liability but not criminal liability.
} 
requirements for consent to medical treatment include duties to inform the patient of the risks of treatment, duties that have no analogue in most other contexts in which actors consent to physical contacts. And conduct that suffices as consent for purposes of a false imprisonment claim might well not suffice for purposes of a battery claim. If store personnel ask a suspected shoplifter to come with them to a back room, where they suddenly reach into her pocket or pocketbook to search for stolen items, it is likely that her choosing to accompany them will be deemed legal consent to what otherwise would be an unlawful confinement, but unlikely that her conduct will be treated as consent to what otherwise would be a battery.

Finally, the proper remedy for conduct that is tortious because of lack of consent depends on why consent is required and on precisely how the consent was deficient. As we have seen, a remedy will be awarded for a battery or false imprisonment even absent proof of resulting physical or emotional harm. What if the defendant never even sought the victim's consent, but the victim would have consented? This, too, seems an appropriate case for a remedy to address the dignitary injury, and some courts have so held. However, in the analogous context of breach of the duty of informed consentwhere medical personnel fail to provide adequate information to a patient about the risks of a proposed medical treatment- the standard American approach is to deny any remedy unless the patient can show that he (or, in many jurisdictions, a reasonable patient) would have decided differently and thus would have avoided the physical harm he suffered from the treatment. This requirement to show "decision causation" is defensible, though only if the failure to obtained informed consent is properly conceptualized as a negligence claim; and only if we are justified in requiring proof of physical harm, not just dignitary injury, for this type of negligence claim.

\section{Comparing consent (IT) with AR}

Let us now take a closer look at the issues identified in the introduction, especially the surprisingly narrow scope of AR. This section will first analyze paradigm instances of consent (IT) and AR. Next, we will identify an "apples and oranges" difficulty in comparing the two doctrines: the doctrines can apply to different types of 
tortious wrongs. We will then consider, and reject, the possible criterion that consent (IT) applies only when $\mathrm{P}$ believes that the harm or the tortious conduct is highly probable, while AR applies only when he believes that these are unlikely to occur. Finally, the concluding subsection will explain that factual differences between paradigm consent (IT) and AR scenarios partially justify their different treatment, but that the consensual rationale underlying many AR cases is too often neglected. ${ }^{22}$

\section{A. Distinguishing paradigm instances of consent (IT) and AR}

Consider first some paradigm cases over which there is no disagreement. The Houdini case is a paradigm instance of consent (IT). Absent Houdini's agreement to be punched, the conduct of the other would constitute an intentional battery (a purposeful or knowing touching); and, at the time Houdini consents, he believes that the other is very likely to engage in such conduct. ${ }^{23}$ Pascal is a paradigm instance of AR. Absent Pascal's agreement to Rascal's driving at a high rate of speed, defendant Rascal's conduct would be considered negligent towards plaintiff Pascal; and, when Pascal agrees to Rascal's dangerous conduct, Pascal believes that the relevant risk of physical harm that Rascal has created or is about to create is only a possibility of harm, not a very high likelihood.

But it is unclear which features make these cases "paradigm." For there are actually three distinctions at play here-(1) between a low and high probability that the relevant (otherwise tortious) conduct will occur; (2) between a low and high probability that harm, offense, or some other legally compensable result of that conduct will occur; and (3) between legally valid consent to a tort of negligence ${ }^{24}$ and legally valid consent to an intentional tort. Which factor matters? The characterization "AR" could mean any or all of the following:

(1) The consenting actor believed there was a low rather than high probability that the other would act tortiously (either negligently or by committing an intentional tort); or

\footnotetext{
${ }^{22}$ For some prior analyses of the issue, see Simons, Full Preference, at 248-258 (and sources cited therein); Simons, Reflections, at 518-525.

${ }^{23}$ To simplify matters, assume that the student asked Houdini if he could punch Houdini in the stomach, and Houdini said yes.

${ }^{24} \mathrm{AR}$ rather than consent is also the terminology typically used for acceptance of the risks arising from torts of recklessness or strict liability.
} 
(2) The consenting actor believed there was a low rather than high probability that harm (or some other compensable injury) would result from the other's tort; or (3) The actor consented to otherwise negligent conduct rather than to an intentional tort.

Insofar as many jurisdictions interpret AR much more narrowly than consent (IT), this is not merely a terminological dispute. Suppose, at the time of his alleged consent, plaintiff agrees to accept a small risk that a later intentional battery will occur. This counts as AR under (1) but not under (3). It is also a quite common scenario, for it frequently arises in sporting and recreational activities. Consider the physical contacts that often occur in soccer, baseball, and many other sports. Should the narrow (or nonexistent) defense of AR apply here, or instead the apparently broader defense of consent (IT)?

Moreover, although (2) is more often satisfied in negligence cases than in intentional tort cases, this relationship is contingent. Sometimes the relevant tortious conduct is at worst negligent, yet the plaintiff believes that the tort is quite likely to result in harm. This counts as AR under (3) but not under (1) or (2). (Suppose a suicidal pedestrian waits for a speeding car and then leaps into the car's path.) ${ }^{25}$

We obtain little guidance on the question from actual judicial practice. Most courts, insofar as they explicitly addressed the issue, endorse (3) rather than (1) or (2) as the criterion for distinguishing AR from consent (IT). ${ }^{26}$ At the same time, courts also frequently address the issue of whether and when participants and spectators in recreational and sporting activities are barred by consent, and in this context some use the language of "consent” while others prefer the language of "assumption of risk.” For purposes of clarity, it would certainly be useful if we had distinct terms for these different concepts. $^{27}$

\footnotetext{
${ }^{25}$ Moreover, in some rescue cases, the defendant's negligence prompts plaintiff to try to save his own life or the life of another in a manner that he realizes is quite likely to lead to harm. However although some courts treat a choice to rescue as an instance of either consent (IT) or AR, I believe we have good reason to treat most rescues as not falling within either category.

26 "Consent to conduct that is merely negligent, creating an unreasonable risk of harm, is commonly called 'assumption of risk."” Restatement (Second) of Torts § 892 comment a (1965).

${ }^{27}$ The following terminology might be suitable for the three categories:
} 
How should we distinguish AR from consent (IT)? Or should they be distinguished at all for legal purposes? We shall see that (3) is not, by itself, a satisfactory distinction, because it compares apples with oranges. I will then show that (1) and (2), although coherent distinctions, do not justify treating AR differently from consent (IT) for purposes of applying consent principles, though they sometimes justify differential judgments of comparative fault. Finally, we will see that paradigm cases of AR and consent (IT) are indeed often distinguishable, but only because of contingent factual differences that often attend such paradigm cases, not because they different in underlying rationale.

B. The apples and oranges problem

The usual manner of comparing $\mathrm{AR}$ and consent (IT) poses a serious and insufficiently appreciated problem: when the comparison takes the form of version (3) above, we are comparing apples and oranges. ${ }^{28}$ The interests protected by the various intentional torts, including battery, are not just the same interests protected by negligence, but protected against intentional as opposed to unintentional invasion. Rather, the intentional torts protect some rights and interests not protected by negligence law at allfor example, the right to autonomy with respect to one's bodily integrity, which is violated by a nonconsensual touching; and the right to freedom of movement, which is violated by a nonconsensual confinement. If an actor unintentionally trips against someone, touching him without his consent, that is neither a battery, nor a viable negligence claim, nor any other tort. ${ }^{29}$ If an actor carelessly but unknowingly locks someone in a room, confining him without his consent, that is neither false imprisonment nor any other tort.

Thus, although it is commonly assumed that intentional torts reflect a more egregious type of fault than torts of negligence, this is not invariably true. More precisely, it is only true insofar as the intentional tort in question implicates precisely the same right

(1) "consented to [the specified tortious] conduct" or "was willing that D engage in [that conduct]";

(2) "assumed the risk of harm [or offense, etc.] from [the specified conduct]"; and

(3) "consented to D's negligence" or "to [what otherwise would be] D’s intentional tort."

${ }^{28}$ See Kenneth Simons, “A Restatement (Third) of Intentional Torts?,” 48 Ariz. L. Rev. 1061 (2006), 10801083.

${ }^{29}$ Negligence liability requires physical harm; but one can commit a battery without causing physical harm. 
or interest as the corresponding tort of negligence. ${ }^{30}$ Thus, it is true in the following situation. Negligently causing physical harm is one type of fault. Intentionally (i.e., knowingly or purposefully) causing the same type and degree of physical harm is indeed ordinarily a more serious form of fault. And a similar hierarchy of fault ordinarily obtains when we compare intentionally or recklessly causing emotional distress with negligently causing the same type and degree of emotional distress.

Yet there is no recognized intentional tort in Anglo-American law that corresponds directly to the general duty not to negligently cause physical harm (nor to any other duties not to negligently harm others). The tort of harmful battery, i.e. battery that causes physical harm, is the best candidate. But it does not fully correspond. Battery, of course, requires a physical contact. So, even in those jurisdictions in which harmful battery requires an intention to cause physical harm, ${ }^{31}$ the tort also requires that such harm be caused by means of the defendant's contacting the plaintiff's person (or something closely connected with his person). A defendant does not commit a battery if he purposely or knowingly causes physical harm to the plaintiff by some other means. If Katie abruptly breaks up with her boyfriend Tom, knowing that, given his sensitive disposition, this will cause him serious emotional distress and resulting physical illness, she has not committed a battery. ${ }^{32}$

\section{A possible criterion: plaintiff's belief about the probability of harm}

Nevertheless, it is illuminating to consider how the distinction between AR and consent (IT) would play out if the law did recognize a general intentional tort of “intentionally (i.e. purposely or knowingly) causing physical harm,”33 corresponding to

\footnotetext{
${ }^{30}$ Indeed, it is not always true even in this situation. Even if knowingly causing physical harm to another is a prima facie tort, it is not always more blameworthy or a more serious type of fault than negligently causing physical harm to another. The first is sometimes justified by necessity or self-defense. But the second is by definition unjustifiable, given the usual understanding of negligence as an all-thingsconsidered judgment of fault.

${ }^{31}$ American jurisdictions are split on this question. Some require only the single intent to cause a contact that is unpermitted and that causes physical harm or offense; others also require the intent to cause physical harm or the intent to cause offense.

${ }^{32}$ Or, if a malicious or indifferent doctor fails to prescribe a medicine for P's severe illness that proper medical care requires, knowing that her omission will cause $\mathrm{P}$ serious physical pain and suffering, the doctor is not liable for a battery.

${ }^{33}$ See Restatement (Third) of Torts, Physical Harm, §3: “An actor who intentionally causes physical harm is subject to liability for that harm.”
} 
the well-recognized general tort of negligently causing physical harm. Indeed, suppose that all the intentional torts were simply "higher culpability" versions of corresponding torts of negligence: intentionally inflicting severe emotional distress would then be the more culpable variant of negligently inflicting severe emotional distress, and so forth.

In this imaginary legal world, the objects of AR and of consent (IT) would both be apples, rather than apple and orange. But the consensual object of AR would be a smaller apple (otherwise tortious conduct that negligently risks harm) while the object of consent (IT) would be a larger one (otherwise tortious conduct by which the actor intends to cause harm). How, in this world, would AR and consent (IT) operate, and how would they relate to each other? The question is instructive. Answering it should help us determine whether the complexity of the relationship between AR and consent (IT) is due to the complexity and incommensurability of extant negligence and intentional tort doctrines, or instead is due to something special about how the concept of consent operates when the object of that consent is a tort reflecting a lower rather than higher degree of fault. (The former, we will see, is closer to the truth.)

Thus, compare two situations: in one, marked as (a), V1 consents to D1 acting in a way that each knows is very likely to cause a minor personal injury to V1; in the other, marked as (b), V2 consents to D2 acting in a way that each knows creates a small risk (but not a high likelihood) of causing a minor personal injury to $\mathrm{V} 2 .^{34}$

\section{Scenario 1: Boxing and tennis}

(a) Victor agrees to a friendly boxing match with Dennis. Both know that Dennis is very likely to land blows that are very likely to cause Victor at least minor physical harm. Victor is injured by one of Dennis's blows.

(b) Vicky agrees to a friendly tennis match with Debby. Both know that in the course of the match, there is a small chance that Debby will cause Vicky at least minor physical harm by accidentally striking Vicky with a tennis ball that Debby hits during play. Vicky is injured in this manner.

\footnotetext{
${ }^{34}$ These two scenarios focus on factor (2) above. Analogous scenarios could be created for factor (1).

The two scenarios each involve knowledge. One could formulate analogous consensual scenarios involving purpose to cause (a) minor physical injury or merely (b) a risk of minor physical injury, e.g. cases of sadomasochistic sexual conduct. The latter scenarios will arise less often, so I focus instead on scenarios involving knowledge that one will or might cause harm.
} 
Is consent more likely to bar recovery in Scenario 1(a) (where the conduct is otherwise an intentional tort) than in Scenario 1(b) (where the conduct is otherwise at worst a tort of negligence)? $?^{35}$ In these examples, there seems to be no relevant difference: if the assent to each match is equally voluntary and if the two victims are equally knowledgeable about the degree of risk, then consent should be equally effective.

At the same time, analogous unilateral scenarios would be equally nonconsensual:

Scenario 2: Unilateral boxing and unilateral striking of tennis ball

(a) Dennis suddenly approaches Victor and lands several punches to Victor's face. (Both again know that this is likely to cause some physical harm.) Victor is injured by one of Dennis's blows.

(b) Debby suddenly approaches Vicky and hits a tennis ball in her direction. (Both again know that this poses a small risk of causing some physical harm.) Vicky is injured.

This second set of scenarios still yields no difference between (a) consent (IT) and (b) AR.

For our next variation, suppose the injurer again acts unilaterally, but the victim thereafter has an opportunity to choose whether to confront either the high or low risk of harm.

Scenario 3: Threat to punch or to strike with a ball

(a) Dennis suddenly approaches Victor and threatens to punch him in the face. Victor says nothing. Dennis makes good his threat, injuring Victor. (Both again know that the threatened action is likely to cause some physical harm. $)^{36}$

(b) Debby suddenly approaches Vicky and threatens to hit a tennis ball in her direction. Vicky says nothing. Debby makes good her threat by hitting the ball, which injures Vicky. (Both again know that the threatened action poses a small risk of causing some physical harm.)

\footnotetext{
${ }^{35}$ Under current law, Vicky might, absent consent, still be liable for a battery. But for purposes of this discussion, we are assuming that battery requires purposely or knowingly causing harm, a level of fault that Vicky lacks.

${ }^{36}$ See Restatement (Second) of Torts §892, Illustration 4: In the course of a quarrel, A threatens to punch B in the nose. B says nothing but stands his ground. A punches $B$ in the nose. $A$ is not justified upon the basis of apparent consent.

The Illustration demonstrates that A cannot successfully invoke either B's actual consent or B's "apparent consent," because a reasonable person in A's shoes would not conclude that B actually consented.
} 
Here, too, there seems to be no relevant difference that affects whether the victim should be able to recover in full. Neither has actually consented to the tortious conduct of the other. And neither victim is negligent.

But consider yet another variation that might justify different results in the two scenarios—namely, "rescue” scenarios that differ greatly in the probability that the victim will suffer harm.

\section{Scenario 4: Rescuing a smartphone}

(a) After crossing the road, Victor realizes that he dropped his smartphone in the middle of the road. He decides to retrieve it, even though he sees that driver Dennis is speeding nearby and that Dennis is very likely to run into him and cause him injury. (Dennis recognizes this as well.) Dennis's car hits Victor, causing injury.

(b) After crossing the road, Vicky realizes that she dropped her smartphone in the middle of the road. She decides to retrieve it, even though she sees driver Debby speeding half a block away. Vicky recognizes a very small chance that Debby will not be able to stop in time and will cause her injury. Debby's car hits Vicky, causing injury.

In this scenario, a jury is justified in finding Victor contributorily negligent, but is not so clearly justified in finding Vicky to be contributorily negligent. The obvious difference between the cases is that an actor's modest interest in saving his property is insufficient to outweigh a high risk of self-injury but might suffice to outweigh a much lower risk of the same harm. ${ }^{37}$

What is telling, however, is that the only instances in which the proper legal treatment of the scenarios differs are those in which a substantial decrease in the probability of risking harm to oneself changes the actor's conduct from unreasonable to reasonable (or at least from highly unreasonable to mildly unreasonable). But there is no reason why we should treat such a decrease in perceived probability of self-harm, without

\footnotetext{
${ }^{37}$ On the other hand, Dennis is more culpable than Debby insofar as the risk of harm he believes he is posing is higher than the risk of harm that she believes she is posing. That militates in favor of Dennis's victim obtaining a larger portion of his damages than Debby's victim obtains (under comparative apportionment). We could isolate these contrasting features, of the degree of fault of the victim vs. the degree of fault of the injurer, by modifying the scenarios. Suppose Victor believes he is very likely to be injured, but Dennis believes he is not very likely to injure (or vice versa). I will spare the exasperated reader the burden of reading four (or eight) more scenarios.
} 
more, as transforming an actor's conduct from consensual to nonconsensual. Thus, in Scenario 4, neither victim consents to the driver's speeding.

Reconsider the five introductory examples. In all of the examples, an increase or decrease in the probability of self-harm does not change whether the victim consented, though in some, it might change whether, and to what extent, the victim's conduct was unreasonable. $^{38}$

D. Factual differences between paradigm consent (IT) and AR scenarios

If the arguments thus far are correct, a consensual rationale underlies many cases conventionally categorized as AR as well as cases of consent (IT), and that rationale is not undermined simply because the consenting party believes the tortious conduct or the resulting harm is improbable rather than probable.

Why, then, have so many courts flatly rejected AR? This section addresses one set of reasons: quite often in paradigm AR scenarios, the consensual rationale is factually inapplicable, while in paradigm consent (IT) scenarios, that rationale is much more likely to apply, either because the two parties mutually benefit from the interaction, or because the allegedly tortious party justifiably relies on the other's assent. ${ }^{39}$ It is perfectly defensible to take these factual differences into account, but this is quite consistent with the point that the same consensual rationale underlies those cases in which courts properly recognize AR and consent (IT).

Situations in which a person consents to a potentially harmful battery very often involve mutual benefit—for example, medical treatment, other physical therapies, sexual relations, and contact sports and recreational activities. Many other consent (IT) cases at least involve reliance by $\mathrm{D}$, who engages in a potentially dangerous activity only after

\footnotetext{
${ }^{38}$ In all of the cases from the introduction, a difference in the probability of harm might affect whether (or the extent to which) the victim is acting unreasonably and thus whether he should, on a comparative fault assessment, obtain a lesser recovery for the harm. (In Jane's case, the probabilities are unlikely to matter unless she knows she is very likely to die from running into the traffic.)

Of course, the reason why the actor is choosing a risky option is highly relevant. If Jane were running across a busy street in order to avoid being tagged in a game of touch football, she could easily be found CN.

${ }^{39}$ Another important reason is that courts sometimes preclude tort liability by recharacterizing AR cases as cases falling within "no duty" or "limited duty" rules. Thus, instead of saying that Scott assumes the risk, they might say that Dot owes only the limited duty to warn him of the risks. See Simons, Reflections, at 497-503.
} 
discovering or reassuring himself that $\mathrm{P}$ assents. But many $\underline{\mathrm{AR}}$ scenarios involve no such mutual benefit, so it is much less clear that the consent is sufficiently voluntary. Often, D acts, then sets the stage for $\mathrm{P}$ to choose whether or not to accept the risk D has created; but at that point, P's choices might be so constrained that it is unjust to treat him as consenting to the dangerous condition. (This is often true of unsafe conditions that employees face in the workplace.) Similarly, many AR scenarios contain no reliance by D, so D has no valid complaint that recovery would be unjust on that ground. Often, D is not in a position even to know whether P does accept the risk. And even if he does know, $\mathrm{D}$ might not be in a position to minimize or eliminate the risk. On the other hand, in those AR scenarios where both parties do benefit from the risky activity, or where D relies on P's willingness to run the risk, the case for denying recovery is much stronger. (Recall Pascal and Scott, ${ }^{40}$ from the introduction.)

In many consent (IT) cases, moreover, the parties do not simply mutually benefit from a particular type of invasive or risky activity: they specifically choose to engage in an activity at a particular level, or characterized by a particular quality, of risk. Houdini can choose to be punched once or many times, or to be pinched rather than punched. A group of friends can play touch or instead tackle football. This power to choose the "rules of engagement," to adjust the risk levels to the preferences of the other or others, differentiates typical consent (IT) from typical AR scenarios. It is thus understandable and defensible that courts more readily exclude liability in consent (IT) scenarios.

Consider a related question: is apparent AR a defense in jurisdictions recognizing $\mathrm{AR}$, in the same way that apparent consent (IT) is as much a defense as actual consent (IT)? Suppose a medical patient tells his doctor that he understands the nature of the operation she is proposing, but actually, he is afraid to admit that he does not. Apparent consent (IT) will protect the doctor from tort liability because she has a reasonable basis for believing that $\mathrm{P}$ actually consented. Does apparent AR similarly protect a $\mathrm{D}$ when $\mathrm{P}$ does not actually agree to accept a risk but $\mathrm{D}$ reasonably believes that he does?

\footnotetext{
${ }^{40}$ Scott is an example of reliance if the rink operator was considering closing down the rink but left it open to accommodate Scott.
} 
The doctrinal answer is unclear, ${ }^{41}$ but I believe the dearth of such cases is simply due to the paucity of occasions in which $\mathrm{D}$ justifiably relies on P's apparent AR. If such an occasion did arise, however, then apparent AR is as defensible a doctrine as apparent consent (IT). Thus, in the Scott example from the introduction, suppose Dot, the rink owner, reasonably believes that Scott fully understands the rough condition of the ice (based on Scott's answer to his question), but Scott in fact does not appreciate the risk. If Dot therefore permits Scott to continue to skate, she should be able to rely on apparent AR to preclude Scott's recovery for his resulting injuries.

Indeed, in one important category of cases, apparent AR is implicitly recognized. When individuals agree to play a sport or engage in a recreational activity involving physical contact, courts often apply a special set of rules. They frequently deny recovery for ordinary negligence, and impose only a limited duty not to recklessly or intentionally cause harm by taking risks that are not inherent in the sport or activity. To some extent, this set of rules reflects the risks to which the parties actually do and do not consent. But the rules require no individual inquiry into how knowledgeable and voluntary the plaintiff's choice to accept the risk was. So they might implicitly reflect the view that a reasonable person in the defendant's shoes would believe that the plaintiff consented, even if a particular plaintiff did not consent. However, I concede that the rules also go further than this: they recognize that the enthusiastic and fervent participation in sports and games is socially valuable and thus might justify making participants responsible for the inherent risks of such activities, apart from either the participants' actual or apparent consent.

Finally, if a jurisdiction interprets AR according to the narrow "full preference" approach that I endorse, ${ }^{42}$ AR can easily be reconciled with consent (IT). In a typical AR case, $\mathrm{D}$ has breached her duty to $\mathrm{P}$ to provide a less risky option, but that option is not available to $\mathrm{P}$ at the time he encounters the risk. Instead, $\mathrm{P}$ is faced with a difficult and unfair choice-whether to engage in a desired activity yet confront the negligently created risk, or not to engage in the activity at all. The third option-engaging in the

\footnotetext{
${ }^{41}$ Simons, Assumption of Risk, at 251-252. See Restatement (Third) of Torts: Apportionment of Liability $3 \mathrm{cmt}$. c ("Whether the defendant reasonably believes that the plaintiff is aware of a risk and voluntarily undertakes it may be relevant to whether the defendant acted reasonably.").

${ }^{42}$ See Section II above.
} 
activity while facing a lesser risk-is usually not open to P. (Skaters in the Scott scenario are faced with the decision whether to skate on dangerous ice or instead wait until tomorrow to skate; they lack the third option to skate now on safe ice.) By contrast, in a typical consent (IT) case, if D offers $\mathrm{P}$ the choice of a dangerous interaction or no interaction, there is no unfairness in asking $\mathrm{P}$ to make that choice, because he can readily avoid the interaction altogether. If the student who approached Houdini proposed punching him in the stomach with brass knuckles, it would have been easy enough for Houdini to decline. And normally, unlike an actor who is negligent towards $\mathrm{P}$, an actor who is alleged to be an intentional tortfeasor has no duty to offer a third, less dangerous option. $^{43}$

\section{Conclusion}

This inquiry into the relationship between consent (IT), AR, and CN has offered some specific lessons and has also unearthed some broader themes. The lessons include the following:

- Often, when P consents to D's engaging in conduct $\mathrm{x}$, knowing that D might engage in somewhat different conduct y or might create a risk of harm y, P is deemed to legally consent to $\mathrm{y}$. Whether it is justifiable to hold $\mathrm{P}$ to this kind of "package deal" depends on the nature of the rights that the particular tort protects.

- Many consent (IT) cases therefore actually involve AR with respect to a risk of harm, in the sense that the actor is deemed, as a matter of law, to have no basis for complaint when the harm occurs, even if the actor did not assent to that risk of harm, considered by itself.

- Is AR normatively distinguishable from consent (IT)? The answer depends on how one distinguishes them-according to the nature of the tort consented to,

\footnotetext{
${ }^{43}$ Normally, but not always. Suppose P goes to an emergency room, the only doctor on duty is drunk, and $\mathrm{P}$ assents to being treated by him, given the dire circumstances. $\mathrm{P}$ does of course have a negligence claim if the doctor provides substandard care that results in physical harm. If the doctor treats him with reasonable care but the operation causes a harmful side effect, it would be plausible to permit a battery claim, because P did not consent to being treating by an intoxicated doctor, and the doctor had a duty to provide medical care in a sober condition.
} 
the likelihood that the tort will occur, or the likelihood that the tort will result in harm.

- Comparing the interests protected by the right not to be negligently harmed with the interests protected by the various intentional torts compares apples with oranges.

- Consent (IT) and AR (when appropriately narrowed) are equally valid bases for precluding recovery.

- It is justifiable to invoke consent (IT) more often than AR, not because the doctrines differ in principle, but because of factual differences between the most common scenarios in which each arises. In paradigm consent (IT) scenarios, the two parties mutually benefit from the interaction, or the allegedly tortious party justifiably relies on the other's assent. These features support the consensual rationale underlying both doctrines, but they are often absent in AR scenarios.

The analysis also has two broader implications. The first concerns the role of reasonableness and consent in tort doctrine and theory. Reasonableness is not all that matters. To be sure, comparative fault principles give significant weight to the fault of the various parties, judged by whether they departed from a standard of reasonable care. But principles of consent often trump reasonableness, either as complete defenses or as crucial components of no-duty or limited-duty rules.

The second broader implication is that Anglo-American tort law is pluralistic. The rights and interests protected by tort law, and the manner by which they are protected, are varied. A single, unified hierarchy cannot explain these phenomena. That is one reason why it is so difficult to compare AR and consent (IT).

For those seeking theoretical and doctrinal simplicity and purity, pluralism is an unfortunate state of affairs. But it is the only authentic explanation of the complexities and tensions within Anglo-American tort law. And I see more reason to celebrate than to regret that heterogeneity. 